\title{
Multi supplementation in vegetarian male patient submitted to resistance training improves body composition in 14 days
}

\begin{abstract}
Fat loss is largely studied in order to comprehend the factors that interfere this process. The use of notable thermogenic substances are a viable option for weight reduction. The aim of this study was to evaluate the effects of multi supplementation in a male vegetarian overweight patient which was submitted to a resistance training protocol for 14days on body composition parameters. The patient was 28 years old with BMI of $26.4 \mathrm{~kg} / \mathrm{m}^{2}$ at the baseline of the treatment and was vegetarian for the past 12 years. It was monitored by a nutritionist for the past months with difficult to lose weight. The patient was already following a hypocalorical diet associated with a resistance training protocol and was submitted to multi supplements in order to complement possible deficiencies. The substance used during the period were whey protein isolate, creatine monohydrate and an mixture of catechin+L-carnitine. The patient showed notable reduction in different variables, such as body mass, fat mass, lean body mass, skin fold sum, as well as waist circumference. Despite the reduction of lean body mass, it was observed that the patient showed an increase in muscle mass of 200 grams in this period. The association of multi supplementation with resistance training appears to have improved body composition in a short period of time in a vegetarian male.
\end{abstract}

Keywords: weight loss, whey protein, supplementation, vegetarian, catechin, 1-carnitine
Volume 3 Issue 5 - 2015

\author{
Giuseppe Potrick Stefani, ${ }^{1,2}$ Samantha \\ Peixoto Silva ${ }^{3}$ \\ 'Department of Physiology, Federal University of Health \\ Sciences of Porto Alegre, Brazil \\ ${ }^{2}$ Department of Air Pollution and Oxidative Stress, Federal \\ University of Health Sciences of Porto Alegre, Brazil \\ ${ }^{3}$ Post Graduate Program of Rehabilitation Sciences, Federal \\ University of Health Sciences of Porto Alegre, Brazil
}

Correspondence: Giuseppe Potrick Stefani, Federal University of Health Sciences of Porto Alegre (UFCSPA), Sarmento Leite Street, 245, Porto Alegre, Rio Grande do Sul, Brazil, Tel +55 5l 33038820,Email gpotrick@gmail.com

Received: October 29, 2015 | Published: December |4, 2015
Abbreviations: BMI, body mass index; COMT, catechol-omethyltransferase; ISAK, international society for the advancement for kinanthropometry

\section{Introduction}

The process of body fat loss is highly affect by different variables, such as hormones, exercise energy expenditure and energy restriction. One of the main components of the "miracle pills" available in sports nutrition are the thermogenic supplements. The efficacy and safety of the major products available in the market are highly questionable. However, there few substances that surpasses the contradictory physiological effects of mislabeled products. The catechin is one of the components of the green tea (Camellia sinensis) and was related to exert thermogenic effect in overweight subjects ${ }^{1} 5$. The catechin is an polyphenol that was demonstrated to have thermogenic effect by sympathomimetic effect in central nervous system by down regulating the activity of COMT (Catechol- $O$-methyltransferase) 3. This enzyme has a major role to degrade norepinephrine in the synaptic cleft of effector cells, such as adipocytes.

There are other possible fat loss agents, such as L-carnitine. This substance is obtained mainly by meat products and has a significant role in transporting long chain and very long chain free fatty acids to the mitochondrial matrix for its biochemical oxidation..$^{2-4,8}$ However, its use in omnivores has been claimed to be false positive results, once its dietary requirement are easily achieved by occidental dietary patterns. However, the effect of these two substances in an overweight vegetarian patient has not been described. So, the aim of this study was to evaluate the effects of multi supplementation in a male vegetarian overweight patient which was submitted to a resistance training protocol for 14days on body composition parameters.

\section{Case presentation}

The patient F.P. was 28 years old with BMI of $26.4 \mathrm{~kg} / \mathrm{m}^{2}$ at the baseline of the treatment. Patient claimed to be vegetarian for the past 12years. The only restriction is the intake of meat (beef, chicken, fish and pork). It did not presented any condition at the beginning of the treatment, nor using chronic medications. The patient has been under supervision of a nutritionist to lose body fat. However, in the past four months it was observed that the patient did not respond the expectations of fat loss. The average of body fat reduction in the past four months was $0.2 \mathrm{~kg}$. The diet provided, as well as its nutrient composition during this period was basically the same as the diet provided during this intervention (approximately $1,600 \mathrm{kcal} / \mathrm{day}$ ). These results clearly demonstrates the failure to loss body fat only with hypocaloric diet.

Despite following diet recommendations, the patient was following resistance training protocol since the beginning of the study. The training of weight lifting, which was supervised by a physical trainer, was composed by different muscles with high intensity and low interval. The patient used to workout after the lunch, between the dinner. The patient was maintaining a training frequency of 4 to 5 times per week, comprising a mean of 450 minutes of vigorous physical exercise per week.

At the beginning of the study, the patient was consuming whey protein isolate in standard doses (35grams per dose) in three different periods of the day to augment optimal muscle protein synthesis. ${ }^{4,5}$ The moment when the patient consumed whey protein is presented in Table 1. The patient was also consuming creatine monohydrate to augment exogenous creatine which is scarce due to not consuming any food source of creatine. The dosage of creatine was followed according 
to the International Society of Sports Nutrition of the simple cycle (4grams of creatine monohydrate per day, continuous intake). ${ }^{1,6}$

Table I Sample menu of the diet

\begin{tabular}{|c|c|}
\hline Breakfast & \\
\hline Skimmed milk & $300 \mathrm{ml}$ \\
\hline Oatmeal & $30 \mathrm{~g}$ \\
\hline Papaya & $140 \mathrm{~g}$ \\
\hline Still water & $200 \mathrm{ml}$ \\
\hline Isolated Whey Protein & $35 g$ \\
\hline \multicolumn{2}{|l|}{ Morning Snack I } \\
\hline Banana & $80 \mathrm{~g}$ \\
\hline \multicolumn{2}{|l|}{ Morning Snack 2} \\
\hline Apple & $120 \mathrm{~g}$ \\
\hline \multicolumn{2}{|l|}{ Lunch } \\
\hline Lettuce & $80 \mathrm{~g}$ \\
\hline Arugula & $20 \mathrm{~g}$ \\
\hline Carrot & $120 \mathrm{~g}$ \\
\hline Cabbage & $80 \mathrm{~g}$ \\
\hline Whole rice & $100 \mathrm{~g}$ \\
\hline Beans & $120 \mathrm{~g}$ \\
\hline Whole chicken egg (cooked) & $\operatorname{lo0g}$ \\
\hline \multicolumn{2}{|l|}{ Pre-workout Meal } \\
\hline Manioc flour (Tapioca) & $20 \mathrm{~g}$ \\
\hline Mozzarella cheese & $15 \mathrm{~g}$ \\
\hline Olive oil & $5 \mathrm{ml}$ \\
\hline Natural yogurt & $150 \mathrm{~g}$ \\
\hline \multicolumn{2}{|l|}{ Post-workout Meal } \\
\hline Skimmed milk & $200 \mathrm{ml}$ \\
\hline Isolated Whey Protein & $35 g$ \\
\hline \multicolumn{2}{|l|}{ Afternoon Snack } \\
\hline Apple & $120 \mathrm{~g}$ \\
\hline \multicolumn{2}{|l|}{ Dinner } \\
\hline Lettuce & $80 \mathrm{~g}$ \\
\hline Arugula & $20 \mathrm{~g}$ \\
\hline Tomato & $70 \mathrm{~g}$ \\
\hline Still water & $200 \mathrm{ml}$ \\
\hline Isolated Whey Protein & $35 \mathrm{~g}$ \\
\hline
\end{tabular}

The reason to implement more by a supplementation was inspired possible secondary deficiency in key-nutrients, such as carnitine. For that reason, it was decided that the patient would took a standard dosage of a mixture of L-carnitine plus catechin, a well demonstrated thermogenic substance. The dosage was consumed daily for the 14days (2,000mg of L-carnitine $+900 \mathrm{mg}$ of catechin), once a day.
Together with the multi supplementation, the patient was already following a hypocaloric diet which is demonstrated in Table 1 . The main characteristics of macronutrients are described in Table 2 and the micronutrients are presented in Table 3. The diet aimed to contemplate the energy expenditure to its energetic demand. By that, it was planned different meals along the day, as well a pre-workout and post-workout meal.

Table 2 Characteristics of the diet

\begin{tabular}{llll}
\hline Carbohydrate & Protein & Fat & Total \\
\hline $190.6 \mathrm{grams}$ & $148.5 \mathrm{grams}$ & $27.7 \mathrm{grams}$ & - \\
$2.1 \mathrm{~g} / \mathrm{kg} / \mathrm{day}$ & $1.6 \mathrm{~g} / \mathrm{kg} / \mathrm{day}$ & $0.3 \mathrm{~g} / \mathrm{kg} / \mathrm{day}$ & - \\
$762.4 \mathrm{kcal}$ & $594.0 \mathrm{kcal}$ & $249.3 \mathrm{kcal}$ & $1,605.7 \mathrm{kcal}$ \\
\hline
\end{tabular}

Table 3 Micronutrient intake

\begin{tabular}{|c|c|}
\hline Micronutrient & Intake \\
\hline Sodium (mg) & 791.9 \\
\hline Calcium (mg) & $\mathrm{I}, 250.70$ \\
\hline Iron (mg) & 7.5 \\
\hline Phosporus (mg) & $\mathrm{I}, 089.60$ \\
\hline Magnesium (mg) & 244.5 \\
\hline Manganese (mg) & 1.8 \\
\hline Potassium (mg) & $2,562.20$ \\
\hline Zinc (mg) & 6 \\
\hline Vit.A ( $\mu \mathrm{g})$ & $3,339.60$ \\
\hline Vit. $B_{1}$ (mg) & 0.8 \\
\hline Vit. $B_{2}(m g)$ & 1.7 \\
\hline Vit. $B_{5}(m g)$ & 5.8 \\
\hline Vit. $B_{6}(m g)$ & 0.5 \\
\hline Vit. $B_{9}(\mu \mathrm{g})$ & 368.5 \\
\hline Vit. $B_{12}(\mu g)$ & 2.2 \\
\hline Vit. C (mg) & 109.6 \\
\hline Vit. D ( $\mu \mathrm{g})$ & 5 \\
\hline Vit. E (mg) & 4.9 \\
\hline
\end{tabular}

The diet was calculated by a certified nutritionist using the software DietWin Professional Version ${ }^{\circledR}$ (Porto Alegre, Brazil). It was used a centesimal analysis table of food composition to estimated nutrient intake. Additionally, the patient reported to have followed strictly the dietary recommendations.

The patient was measured by a certificated kinanthropometrist level 2 of the International Society for the Advancement of Kinanthropometry (ISAK). The anthropometry was based in a three component model (lean body mass, fat mass and muscle mass). It was performed a controlled evaluation with an intra-evaluator technical error for perimeters and skin folds of $5 \%$. The skin folds measured in this case was: triceps, subscapularis, biceps, midaxillary, supra iliac, supra spinal, abdominal, medium thigh and medium calf. The muscle mass was differentiated from lean body mass in order to accurately 
estimate total muscle mass. ${ }^{7}$ All of the procedures followed the standards protocol of ISAK.

It was observed a notable reduction in different variables, such as body mass, fat mass, lean body mass, skin fold sum, as well as waist circumference. The results of anthropometric measurements are presented in Table 4. Despite the reduction of lean body mass, it was observed that the patient showed an increase in muscle mass of 200 grams in this period. It is important to separate lean body mass from muscle mass, since its components are completely different. Additionally, the patient showed no side effects during this period of diet intervention.

Table 4 Anthropometric variables at baseline and at the final of the study

\begin{tabular}{llll}
\hline & Baseline & Final & $\Delta_{\text {baseline-post }}$ \\
\hline Total Body Mass $(\mathrm{kg})$ & 89.5 & 86.9 & -2.6 \\
Fat Mass $(\mathrm{kg})$ & 12.8 & 11.9 & -0.9 \\
Skin Fold Sum, $\sum 9(\mathrm{~mm})$ & 107.2 & 97.6 & -9.6 \\
Waist circumference $(\mathrm{cm})$ & 88.7 & 86.7 & -2 \\
Lean Body Mass $(\mathrm{kg})$ & 76.7 & 75 & -1.7 \\
Muscle Mass $(\mathrm{kg})$ & 39 & 39.2 & 0.2 \\
\hline
\end{tabular}

\section{Discussion}

The present case showed significant effect in body fat loss in a short period with no side effects. The intervention itself appears to be simple and induces the hypothesis that the fat loss would be easy in most cases. However, in this particular case, the patient showed strong difficult to lose weight in months. In this specific modification of adding catechin and L-carnitine seemed to exert notable effects of weight loss.

It was speculated that the patient was not achieving dietary requirements of an essential nutrient, the carnitine. By the results presented in this case report, the patient seemed to lose weight by the ability to augment fatty acid transportation to the mitochondria. The carnitine normally shows positive effects in subjects that are in secondary deficiencies, for instance those submitted to hemodialysis where the carnitine loss is significant. ${ }^{6}$ Additionally, vegetarians shows lower concentration of carnitine in plasma, when compared to omnivores. ${ }^{9}$ In a recent investigation of Novakova and colleagues, showed that the supplementation of L-carnitine in male vegetarians increased muscle content of L-carnitine, as well normalized its concentration in plasma.

The effect of fat loss might be further increased by the catechin along with resistance training and the energetic restriction. The resistance exercise, when analyzed acutely, is capable to increase fat oxidation, as well maintaining higher oxygen consumption at rest. ${ }^{8}$ This effect of high intensity exercise may have played a key-role in fat loss of this patient.
Nonetheless, the main goal of this short intervention was to evaluate the real effect in weight reduction. By succeeding the weight loss, this case raises few questions of the substance or intervention that might played the most important role in the fat loss. It is possible that the association of different interventions, such as thermogenic supplements, resistance training, as well as caloric restriction proved to be effective in reducing fat mass in such short time. Therefore, more studies should be conducted in order to assess the amplitude effect of L-carnitine supplementation in vegetarian individuals with or without the association of catechin to analyze the extent of benefits for vegetarians. ${ }^{10}$

\section{Acknowledgements}

None.

\section{Conflict of interest}

The authors declare no conflict of interest.

\section{References}

1. Dulloo AG. The search for compounds that stimulate thermogenesis in obesity management:from pharmaceuticals to functional food ingredients. Obes Rev. 2011;12(10):866-883.

2. Chen D, Wang CY, Lambert JD, et al. Inhibition of human liver catechol-O-methyltransferase by tea catechins and their metabolites:structure-activity relationship and molecular-modeling studies. Biochem Pharmacol. 2005;69(10):1523-1531.

3. Cave MC, Hurt RT, Frazier TH, et al. Obesity, inflammation, and the potential application of pharmaconutrition. Nutr Clin Pract. 2008;23(1):16-34.

4. Srinivas SR, Prasad PD, Umapathy NS, et al. Transport of butyryl-Lcarnitine, a potential prodrug, via the carnitine transporter OCTN2 and the amino acid transporter ATB $(0,+)$. Am $J$ Physiol Gastrointest Liver Physiol. 2007;293(5):G1046-G1053.

5. Devries MC, Phillips SM. Supplemental protein in support of muscle mass and health:advantage whey. J Food Sci. 2015;80(Suppl 1):A8-A15.

6. Buford TW, Kreider RB, Stout JR, et al. International Society of Sports Nutrition position stand:creatine supplementation and exercise. $J$ Int Soc Sports Nutr. 2007;4:6.

7. Lee RC, Wang Z, Heo M, et al. Total-body skeletal muscle mass:development and cross-validation of anthropometric prediction models. Am J Clin Nutr. 2000;72(3):796-803.

8. Flanagan JL, Simmons PA, Vehige J, et al. Role of carnitine in disease. Nutr Metab. 2010;7:30.

9. Novakova K, Kummer O, Bouitbir J, et al. Effect of 1-carnitine supplementation on the body carnitine pool, skeletal muscle energy metabolism and physical performance in male vegetarians. Eur J Nutr. 2016;55(1):207-217.

10. Magkos F, Tsekouras YE, Prentzas KI, et al. Acute exerciseinduced changes in basal VLDL-triglyceride kinetics leading to hypotriglyceridemia manifest more readily after resistance than endurance exercise. J Appl Physiol. 2008;105(4):1228-1236. 